The International Journal of Engineering and Science (IJES)

|| Volume || 6 || Issue || 6 || Pages || PP 37- 42 || 2017 ||

ISSN (e): $2319-1813$ ISSN (p): $2319-1805$

\title{
Analytical Description of De Motor with Determination of Rotor Damping Constant (B) Of 12v De Motor
}

\author{
Onawola, Hassan Jimoh ${ }^{1,}$ Adewunmi, Olugbenga Titus ${ }^{2,}$ Ehiagwina, Frederick \\ Ojiemhende ${ }^{3,}$ Iromini, Nurudeen Ajibola ${ }^{4}$ \\ ${ }^{1,4}$ Department of Computer Engineering Technology, Federal Polytechnic, Offa, \\ PMB 420, Offa, Kwara State, Nigeria \\ ${ }^{2,3}$ Department of Electrical/Electronics Engineering, Federal Polytechnic, Offa,
}

\begin{abstract}
DC motor as an electric machine have been applied in numerous control systems. However, a critical parameter of interest that must be evaluated in designing a DC motor based system is the damping constant of the rotor. This paper analytically examines how to determine the damping constant of the rotor of a $12 \mathrm{~V} D C$ motor, with the determination based on the following parameters: Armature resistance $\left(R_{a}\right)$, inductance $(L a)$, Capacitance, the Stall current and the Angular rate of excitation of the motor with varying armature excitation of the current. These parameters help to ascertain the maximum and the minimum operating limit of the motor so as not to exceed the boundary-operating limits of the $12 \mathrm{~V}$ motor. Experiments were performed in the laboratory and at the end of the analysis, the result shows that the value of damping constant of a $12 \mathrm{VDC}$ motor was $-3.317 \times 10^{-4} \mathrm{~N}-\mathrm{m}-\mathrm{sec}^{2}$. This parameter can be factored in future control system designs.
\end{abstract}

Keywords: Motor, machines, impedance, armature, inductance

Date of Submission: 17 May 2017

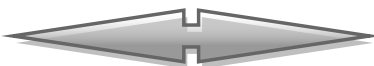

Date of Accepted: 17 June 2017

\section{INTRODUCTION}

A DC motor is the most versatile and widely used rotating electrical machines. Its speed may be easily controlled or adjusted in very fine increments ranging from initial value to rated speed for which the motor was designed for; if the speed is not properly controlled, it may reach speeds high enough to cause destruction to the motor. Meanwhile, speed control of dc motors is achieved by varying the flux $(\phi)$ or the armature resistances Ra. However, if Ra is increased the field current $\mathrm{I}_{\mathrm{f}}$ is decreased. A more insightful overview of DC motor operation and application in control systems are presented in $[3,5,7,9,16]$

There are several reported applications of DC motors which would be discussed in the research study. [15] developed a phase variable model of the brushless DC motor. The model was used to examine the performance of a brushless DC motor speed servo drive system when fed by hysteresis and pulse width modulated current controller. The simulated result revealed that the large- and small signal responses are the same due to similar overall speed response.

Furthermore, two methods based on either voltage model and current model from speed and position sensorless control of permanent magnet brushless DC motor with a sinusoidal flux distribution was reported by [12]

In addition, DC motor was applied in a two-wheeled vehicle because of its configuration with two coaxial wheels with each coupled to it by [6]. Meanwhile, [8] developed electric power steering systems control logic for reduction of steering torque exerted by a driver. It improved the return-to-centre performance and realization of various steering feel. The authors further observed that brushless DC motor possess similar characteristics as DC motor when it comes modelling.

[18] proposes fractional order, Proportional Integral Derivative (PID) control of a DC motor, which possesses elastic shaft, and used for position servomechanism control system. The research considered the torsional flexibility of the motor shaft and actuator saturation. The system has the possibility of better performance in comparison with conventional integer order PID controller.

Furthermore, [2] presented application of DC motor for driving flapping wings at large wing strokes and high frequencies. However, in this case instead of the DC motor rotating, it reciprocates, thus avoiding the use of nonlinear transmission. With this improvement, the proposed system could be deployed in autonomous micro-aerial vehicles. Other applications of DC motors include: electric vehicles [4], granular fertilizer applicator [17], water pump [19], axis solar tracking system [10], knee prosthetic, [1] and so on. Also analysis and description of DC motor was reported in $[13,14]$. 
The response to damping can be under, over and critical damping. The under damped system yields an exponentially decreasing sinusoidal output in response to a step input whereas over damped system yield a nonoscillatory output in response to a step input but has more damping than necessary, in order to achieve the nonoscillatory output. However critical damped systems yield a non-oscillatory output in response to a step input. For $12 \mathrm{~V}$ DC motor to operate efficiently there is a need to know the following parameters as specified by the manufacturer. The minimum and maximum operating limit capacity of the motor, the damping constant $(\beta)$ of the $12 \mathrm{~V} \mathrm{dc}$ and to determine whether the motor is under damping, over damping or critically damped based on these parameters. Damping is the energy dissipation properties of a material or system under cyclic stress. The response of a control system consists two parts that is the transient response and steady state response. Determination of damping constant of motor requires an application that is mathematically inclined, which deals with the basic principles underlying the design and analysis of the system involved.

If transient response $C_{T R}$ and the steady-state response $C_{S S}$, system response is given by equation (1):

$C(t)=C_{T R}(t)+C_{S S}(t)$

For time constant $\tau$, the first order system is given as equation (2)

$C(t)+\tau \frac{\delta t}{\delta t}=U(t)$

Equation (3) is derived by applying Laplace transform to equation (2) with simplification.

$$
\begin{aligned}
& C(s)+\tau(s) C(s)=U(t) \\
& C(s)[1+\tau(s)]=U(s) \Rightarrow \frac{C(s)}{U(s)}=\frac{1}{1+\tau(s)} \Rightarrow C(s)=U(s)\left\lfloor\frac{1}{1+\tau(s)}\right\rfloor
\end{aligned}
$$

Meanwhile, an unforced damped harmonic oscillator has the form of equation (4).

$C^{\prime \prime}+2 \phi \omega n C^{\prime}+\omega^{2} n C=\omega^{2} n C$

Where: $\mathrm{C}$ and $\mathrm{U}$ are function of $\mathrm{t}$.

Mathematically, in most cases over damping is consider appropriate to work with, because the roots are real.

\section{METHODOLOGY}

The values of armature Resistance $R_{a}$, armature inductance $L_{a}$ and Capacitance $C_{a}$ were determined in the laboratory using an instrument called impedance meter and the results obtained are as follows: $\mathrm{Ra}=22.13 \times 10^{3}$ $\Omega, \mathrm{La}=0.125 \mathrm{H}, \mathrm{Ca}=1.702 \times 10^{-8} \mathrm{~F}$.

\section{DETERMINATION OF THE STALL CURRENT OF THE 12V DC MOTOR}

The Voltmeter was connected across the variable power supply; with the ammeter connected in series with motor as shown in fig. 1. The variable D.C source was set to $3 \mathrm{~V}$ with the switch $\mathrm{ON}$, the rotor started to rotate, the armature current on No- load and speed of the motor were measured when the shaft of motor was stalled i.e. (A zero speed), the armature current was found to have increased and the armature current was read from the ammeter.

The Experiment was carried out three more times for different voltage ratings of $4.5 \mathrm{~V}, 6 \mathrm{~V}$ and $9 \mathrm{~V}$ see table 1

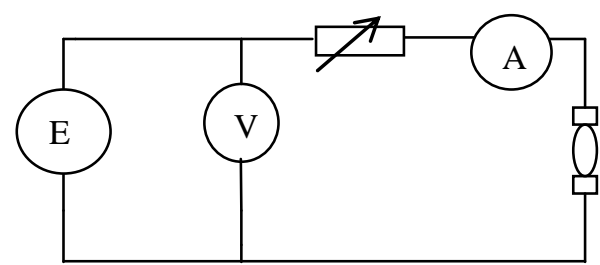

Fig.1: Circuit of speed of a 12V motor on No-load

\section{DETERMINATION OF THE ANGULAR RATE OF ROTATION OF THE 9V DC MOTOR WITH VARYING ARMATURE EXCITATION CURRENT}

A voltmeter was connected across the variable D.C source, Rheostat, ammeter in series with the motor, with the counter attached to the spindle of the motor by means of a belt as shown in fig. 2. The variable D.C source was set to $3 \mathrm{~V}$, the D.C source was then $\mathrm{ON}$ for a period of 15 seconds, the armature current and the speed of the rotor position were read from the counter. The angular rates of rotation $\omega$ were calculated. 
The experiment was carried out for another four more times for different voltage values of $5 \mathrm{~V}, 6 \mathrm{~V}$ and $9 \mathrm{~V}$.See table 2. The angular rotations were also calculated using the expression. $\omega=\frac{\partial \theta}{\partial T}$

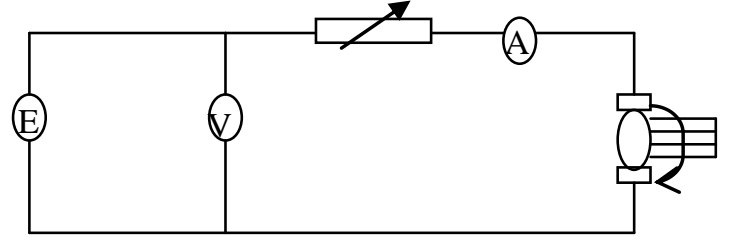

Fig. 2: Circuit of the speed rotational of a $12 \mathrm{~V}$ DC motor

III. DISCUSSION OF RESULTS

Table 1: Results obtained for the speed of a Motor on No-load

\begin{tabular}{|l|l|l|}
\hline $\mathbf{V}(\mathbf{v})$ & Stall Current $\mathbf{I}_{\mathbf{a s}}(\mathbf{m A})$ & No-load current $\mathbf{I}_{\mathbf{a}}(\mathbf{m A})$ \\
\hline 3 & 0.012 & 0.01 \\
\hline 4.5 & 0.07 & 0.05 \\
\hline 6 & 0.135 & 0.10 \\
\hline $\mathbf{9}$ & $\mathbf{0 . 2 8}$ & $\mathbf{0 . 2 5}$ \\
\hline
\end{tabular}

Table 2: Results obtained for the angular rotation of a 9V DC Motor

IV

\begin{tabular}{|l|l|l|l|l|l|}
\hline \multicolumn{1}{|c|}{$\mathrm{V}$} & $\mathrm{I}_{\mathrm{a}}(\mathrm{mA})$ & $\mathrm{T} /($ sec. $)$ & $\theta$ & $\omega(\mathrm{rps})$ & $\omega^{2}(\mathrm{rps})$ \\
\hline 3 & 20.00 & 15 & 143 & 9.53 & 90.80 \\
\hline 5 & 26.30 & 15 & 250.33 & 16.69 & 278.56 \\
\hline 6 & 29.30 & 15 & 289.6 & 19.31 & 372.88 \\
\hline 9 & 30.20 & 15 & 321 & 21.40 & 458.10 \\
\hline
\end{tabular}

ANALYSIS AND DISCUSSION OF RESULTS

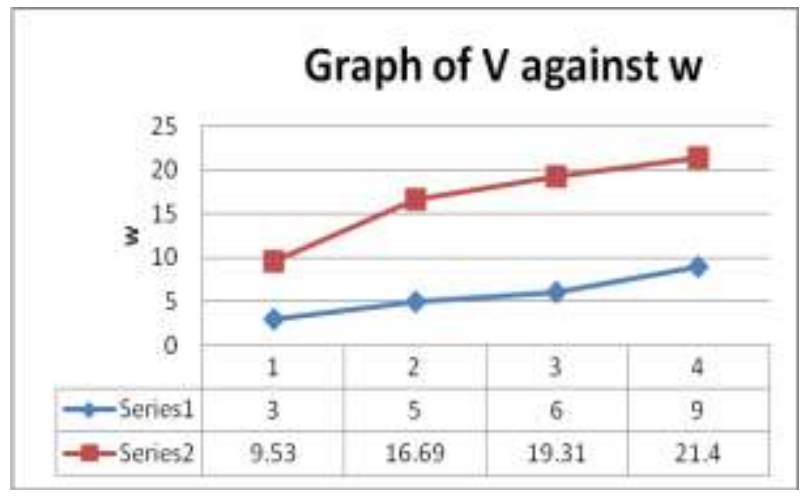

Fig. 1.2a: Graph of V against $\omega$

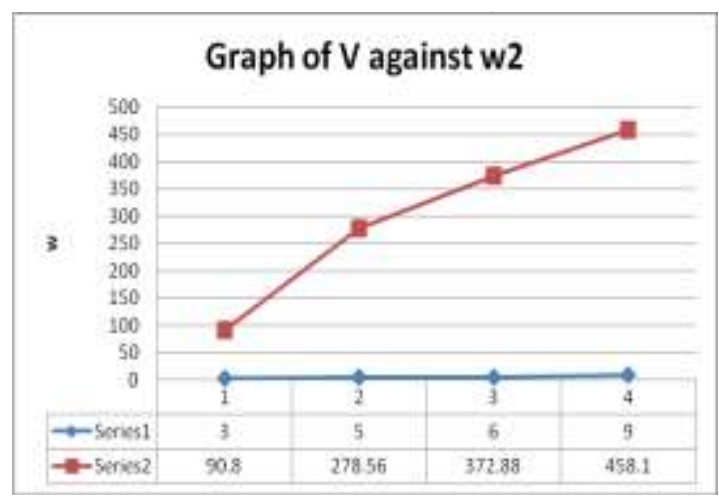

Fig.1.2b: Graph of V against $\omega^{2}$

It is assumed that all initial conditions are zero.

Taking the Laplace transform of equation (4) and further simplification, we obtained equation (5)

$$
\begin{aligned}
& s^{2} C(s)+2 \phi \omega s C(s)+\omega^{2} C(s)=\omega^{2} U(s) \\
& C(s)=\left[s^{2}+2 \phi \omega s+\omega^{2}=\omega^{2} U(s)\right] \\
& C(s)=\frac{\omega^{2}}{s^{2}+2 \phi \omega s+\omega^{2}} * U(s)
\end{aligned}
$$


But $U(s)$ is the unit step, that is, $U(s)=\frac{1}{s}$

Hence, equation (5) becomes the expression shown in equation (6),

$$
C(s)=\frac{\omega^{2}}{s\left(s^{2}+2 \phi \omega s+\omega^{2}\right)}
$$

The solution is of the form, with $p_{1}$ and $p_{2}$ being the poles of the system

$C(s) \equiv \frac{A_{0}}{s}+\frac{A_{1}}{\left(s-p_{1}\right)}+\frac{A_{2}}{\left(s-p_{2}\right)}$

$\left(\mathrm{S}-\mathrm{p}_{1)}\right.$ and $\left(\mathrm{S}-\mathrm{p}_{2}\right)$ are the roots of quadratic equation of the form

$X=\frac{-b \pm \sqrt{b 2-4 a c}}{2 a}$

From equation 4

$$
\begin{aligned}
& s=\frac{-2 \phi \omega \pm \sqrt{(2 \phi \omega)^{2}-4 \omega^{2}}}{2}=\frac{-2 \phi \omega \pm \sqrt{4 \phi^{2} \omega^{2}-4 \omega^{2}}}{2} \\
& =\frac{-2 \phi \omega \pm 2 \omega \sqrt{\phi^{2}-1}}{2}=\frac{-\phi \omega \pm \omega \sqrt{\phi^{2}-1}}{2}
\end{aligned}
$$

When the magnitude is positive, $P_{1}=-\phi \omega+\omega \sqrt{\phi^{2}-1}, P_{2}=-\phi \omega-\omega \sqrt{\phi^{2}-1}$

By partial fraction resolution,

$$
A_{0}=1, A_{1}=-\frac{1}{2}-\frac{\phi}{2 \sqrt{\phi^{2}-1}}, A_{2}=-\frac{1}{2}+\frac{\phi}{2 \sqrt{\phi^{2}-1}}
$$

By applying inverse Laplace transform after substitution, equation $(8)$ is realized.

$$
C(t)=1+A_{1} \ell^{p t}+A_{2} \ell^{p t}
$$

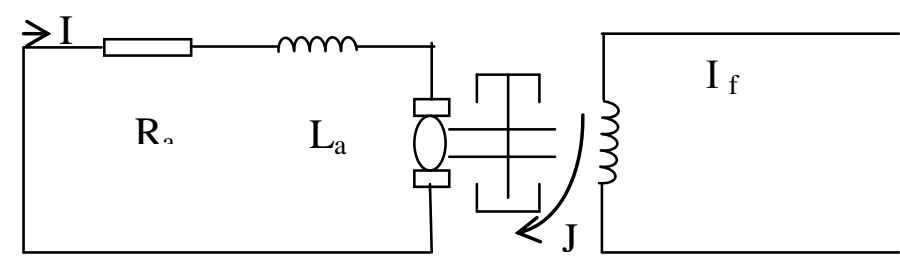

Fig. 3: A schematic of motor generator system with inertia load $\mathrm{J}$, viscous damping $\beta$ at angular velocity

\section{Analysis of the Mathematical Model of DC Motor Operation}

If the torque of the DC motor is $T \mathrm{Nm}$, moment of inertia is $\mathrm{J} \mathrm{Nms}^{2}$ and the damping constant is $\beta \mathrm{Nms}$; then

$$
T=J \ddot{\theta}+\beta \dot{\theta}
$$

Taking the Laplace transform of equation (9) gives equation (10).

$T(s)=J_{s}^{2}+\theta(s)+\beta s \theta(s)$

However,

$$
T \omega=E I_{a}-R I_{a}^{2}
$$

Where:

$E=$ EMF generated by the motor $(V)$

$I_{a}=\operatorname{armature}$ current $(A)$

$R=$ resistance of the motor $(\Omega)$

It is to be noted that equation (9) can be put in the form shown in equation (12). 
$T=J \dot{\omega}+\beta \omega$

Substituting equation (11) into (12), we obtained:

$J \dot{\omega} \omega+\beta \omega^{2}=E I_{a}-R I_{a}{ }^{2}$

Let $K=I_{a}, C=R I_{a}{ }^{2}$ (Ohmic loss). Hence,

$$
J \dot{\omega} \omega+\beta \omega^{2}-K E=-C
$$

Thus,

$E=\frac{1}{K}\left(J \dot{\omega} \omega \beta \omega^{2}+C\right)$

Let $\omega^{2}=x \Rightarrow E=\frac{-\beta}{K} x-J \dot{\omega} \omega$

At the steady state $\omega=0$

$\Rightarrow E=\frac{-\beta}{K} x$

Hence the slope of fig. 3 is equated to the equation to gives the values of $\beta$

i.e $M=\frac{-\beta}{K_{0}}$

Where $\mathrm{K}_{0}=$ Current on No-load.

Similarly Ks =Stall current

$$
\begin{aligned}
& M=\frac{-\beta}{K_{s}} \Rightarrow M K_{s}=-\beta \\
& M=\frac{-\beta}{K_{0}} \Rightarrow M K_{0}=-\beta \Rightarrow M K_{s}=-\beta \Rightarrow-\beta_{0}=M I_{0} \\
& \Rightarrow-\beta_{0}=0.033170 \times 0.01 \times 10^{-3} \\
& =-3.317 \times 10^{-7} N-m-\mathrm{sec}
\end{aligned}
$$

From equation 4

$1=$ Steady State,

$A_{1} \ell^{p t}+A_{2} \ell^{p t}=$ Transient State,

If $\phi \quad<1$; Complex root $\Rightarrow$ under damping, If $\phi \quad>1$; Real \& unequal roots $\Rightarrow$ Over damping, If $\phi \quad=1$; Real \& equal roots $\Rightarrow$ critically damping

\section{CONCLUSION AND RECOMMENDATION}

From the Mathematical Modelling and analysis of $12 \mathrm{~V}$ DC Motor, the value of the Damping Constant $(\beta)$ was found to be $-3.317 \times 10^{-4} \mathrm{~N}-\mathrm{m}-\mathrm{sec}^{2}$. This value is very significant in the determination of damping constant in the designing processes, this value should be taken into consideration when determining whether the damping of a rotor of a motor is under, over or critically damped and should be properly looked into in order to avert under-designing and if this is taken into account, the life span of the motor would be prolonged and unwarranted forms of damages and breakdown of the components of the motor as a result of voltage fluctuation would be averted. However from the analysis Damping Constant of $-3.317 \times 10^{-4} \mathrm{~N}-\mathrm{m}-\mathrm{sec}^{2}<1$ this mean that the value of $\phi$ is complex root meaning that the system is under damping.

\section{REFERENCES}

[1]. Awad, M. I., Dehghani-Sanij, Abass, A., Moser, D., \& Zahedi, S. (2016). Motor electrical damping for back-drivable prosthetic knee. In Mechatronics (MECATRONICS)/17th International Conference on Research and Education in Mechatronics (REM), 2016 11th France-Japan \& 9th Europe-Asia Congress on. IEEE. http://doi.org/10.1109/MECATRONICS.2016.7547167

[2]. Campolo, D., Azhar, M., Lau, G.-K., \& Sitti, M. (2012). Can DC motor directly drive flapping wings at high frequency and large 
wing stroke. Robotics and Automation (ICRA), 2013 IEEE International Conference on, 19(1), 109-120. http://doi.org/10.1109/TMECH.2013.2222432

[3]. Charles, I. H. (2002). Electric Machines: Theory, Operation, Application, Adjustment and Control. Prentice-Hall.

[4]. Febin, J. L. D., Padmanaban, S., Blaabjerb, F., Patrick, W. W., \& Ojo, J. O. (2015). Implementation of wavelet-based robust differential control for electric vehicle application. IEEE Transactions on Power Electronic, 30(2), 6510-6513. http://doi.org/10.1109/TPEL.2015.2440297

[5]. Golnaraghi, F., \& Kuo, B. (2009). Automatic control system (9th ed.). John Wiley \& Sons, Inc.

[6]. Grasser, F., D’Arrigo, A., \& Colombi, S. (2002). Joe: a mobile, inverted pendulum. IEEE Transactions on Industrial Application, 49(1), 107-114. http://doi.org/10.1109/41.982254

[7]. Kathsuhiko, O. (2010). Modern Control Engineering. Prentice-Hall.

[8]. Kim, J.-H., \& Song, J.-B. (2002). Control logic for an electric power steering system using assist motor. Mechatronics, 12(3), 447459. http://doi.org/10.1016/s0957-4158(01)00004-6

[9]. Krishnan, R. (2010). Permanent magnet synchronous and brushless DC motor drives. Boca Raton, FL, USA: CRC Press, Taylor and Francis Group.

[10]. Maharaja, K., Xavier, R. J., Amla, L. J., \& Balaji, P. P. (2015). Intensity based dual axis solar tracking system. International Journal of Applied Engineering Research, 10(8), 19457-19465.

[11]. Matsui, N. (1996). Sensorless PM brushless DC motor drives. IEEE Transactions on Industrial Application, 43(2), 300-308. http://doi.org/10.1109/41.491354

[12]. Matsui, N., \& Shigyo, M. (1990). Bushless DC motor control without position and speed sensors. In Industrial Applications Society Annual Meeting. IEEE. http://doi.org/10/1109/IAS.1990.152224

[13]. Onawola, H. J., \& Adewunmi, O. T. (2008). Design and construction of a Position Controlled DC Motor. Nigerian Journal of Science and Technical Research (NIJOSTER).

[14]. Onawola, H. J., \& Seluwa, E. O. (2005). Determination and Evaluation of Moment of Inertia and Damping Constant of 12V DC Motor. Landzun J.Eng \& Appropriate Tech., 2(2), 30-33.

[15]. Pillay, P., \& Krishnan, R. (1989). Modeling, simulation, and analysis of permanent-magnet motor drives. II. The brushless DC motor drive. IEEE Transactions on Industrial Application, 25(2), 274-279.

[16]. Richard, C. ., \& H.B., R. (2011). Modern Control Systems (12TH ed.). New York: Prentice Hall.

[17]. Su, N., Xu, T., \& Song, L. (2015). Development of a variable rate fertization control system based on DC motor for use on granular fertilizer applicator. In Communication Systems and Network Technologies (CSNT), 2015 Fifth International Conference on (pp. 1203-1209). IEEE.

[18]. Xue, D., Zhao, C., \& Chen, Y. (2006). Fractional order PID control of a DC-motor with elastic shaft: A case study. In Proceeding of the 2006 American Control Conference. Minneapolis, Minnesota, USA.

[19]. Youssef, M. Z. (2015). Design and performance of a cost-effective BLDC drive for water pump application. IEEE Transactions on Industrial Application, 62(5), 3277-3284. 